\title{
Interictal spike quantification in continuous spike-wave of sleep (CSWS): Clinical usefulness of a wearable EEG device
}

\author{
Daniel Carvalho ${ }^{\mathrm{a}, \mathrm{b}}$, Timóteo Mendes ${ }^{\mathrm{c}}$, Ana I. Dias ${ }^{\mathrm{a}}$, Alberto Leal ${ }^{\mathrm{a}, \mathrm{c}, *}$ \\ a Pediatric Neurology (EEG Lab), Hospital Dona Estefânia, Lisbon, Portugal \\ bscola Superior de Tecnologias e Saúde de Lisboa (ESTeSL), Lisbon, Portugal \\ ' Department Clinical Neurophysiology, Centro Hospitalar Psiquiátrico de Lisboa, Lisbon, Portugal
}

\section{A R T I C L E I N F O}

\section{Article history:}

Received 3 September 2019

Revised 2 January 2020

Accepted 2 January 2020

Available online 25 January 2020

\section{Keywords:}

Epilepsy

CSWS

EEG

Wearable

Epileptic encephalopathy

\begin{abstract}
A B S T R A C T
Introduction: Continuous spike-wave of sleep (CSWS) syndrome is one of the most common epileptic encephalopathies of childhood. Because the associated cognitive/behavioral disturbances relate more to the amount of spike activity than of seizures, methods of spike quantification gained relevance in diagnosis and monitoring treatment. The conventional methodology for quantification of spike index (SI) relies on repeated full 10-20 long-term ambulatory electroencephalography (aEEG), which is both expensive and poorly tolerated. Objective: The objectives of this study were to demonstrate the clinical value of repeated SI assessments in CSWS and to build and validate a wearable device allowing inexpensive and well-tolerated, repeated quantifications. Methods: A group of $\mathrm{N}=38$ patients with CSWS were submitted to repeated SI quantifications based on aEEG, as seen fit by the medical clinical assistant. Responses to therapy with corticosteroids $(N=10)$, sulthiame $(N=7)$, and the ketogenic diet $(\mathrm{N}=3)$ were monitored. We used a conventional method based on a semiautomatic template match spike search. The individual variability in time spans of days $(\mathrm{N}=4)$ or months $(\mathrm{N}=10)$ was assessed and used to determine the meaningful neurophysiological responses to the diverse therapies. A wearable device capable of recording 2 bipolar EEG channels for $24 \mathrm{~h}$ was used to simplify SI quantification. Results: Corticosteroids produced the most powerful SI reduction, but a large individual variability in both amount and time of onset of clinical response with some patients exhibiting recurrence shortly after therapy. A more frequent sampling of SI would provide a more accurate follow-up, with clinical benefit.

The comparison of the SI obtained from standard 10-20 electrodes and 2 bipolar EEG channel subsets in aEEG or between the 10-20 and simultaneous wearable recordings, demonstrated that the new method provides an accurate SI quantification.

Conclusions: A wearable EEG device with 2 bipolar channels simplifies the process of obtaining repeated SI quantification allowing a more accurate follow-up of spike activity in the clinical setting.
\end{abstract}

(c) 2020 Elsevier Inc. All rights reserved.

\section{Introduction}

The continuous spike-wave of sleep (CSWS) syndrome, first described in 1971 [1], is a condition of young children where onset of cognitive/behavioral problems (reviewed in [2]) associates with a peculiar type of spike activity, reduced in rapid eye movement (REM) sleep and wakefulness but very abundant during non-REM sleep. The association, strongly suggestive of a causal relationship [3], motivated efforts to quantify the interictal spike activity to distinguish it from similar EEG conditions, but without the cognitive effects, and to monitor response to therapy. Early attempts to quantify the spike index (SI) focused on determining the percentage of non-REM sleep with continuous spiking, using diverse, mostly poorly described, methods (reviewed in [4]). No

\footnotetext{
* Corresponding author at: Avenida do Brasil 53, 1749-002 Lisboa, Portugal.

E-mail address: a.leal@neuro.pt (A. Leal).
}

clear-cut threshold of the SI was firmly established for the appearance of cognitive/behavioral problems and the early proposal of $85 \%$ in the original article [1] persisted as a general historical reference. The introduction of digital EEG in the clinical settings allowed the introduction of more objective and less labor-intensive methods [5], with a significant contribution from the ambulatory electroencephalography (aEEG) to make the task of recording whole night EEG easier.

The significant variability of clinical and neurophysiological features of CSWS throughout the course of the condition, which can extend from the early years of life until adolescence (reviewed in [6]), and the need for prolonged, often poorly tolerated [7], therapies has always functioned as a strong motivation for the objective quantification of spike activity as a monitoring tool (reviewed in [8]). In the clinical setting, the adoption of methods based on repeated aEEGs for detailed analysis has faced with practical difficulties and led to the persistent use of routine sleep studies for such assessments, despite their well-known 
limitations [9]. Several reasons contribute to the relatively poor use of aEEG for monitoring of CSWS, including cost, tolerability, and availability. These limitations led to relatively little data on the individual variability along the natural history of the condition and on the time relationship with recovery from the cognitive/behavioral impairments [8].

In the present paper we proposed to a) determine the variability of SI quantifications over a day-to-day or several months temporal span; b) explore the temporal profile of response to the most common therapies; c) quantify the SI with a full 10-20 montage and with a reduced montage with 2 bipolar electrodes in the same patients; and d) validate a wearable EEG logger to perform repeated SI quantifications throughout the natural history of CSWS.

\section{Patients and methods}

\subsection{Clinical population}

The clinical population $(\mathrm{N}=38$ ) was selected from patients referred to the Electroencephalography Lab of the Department of Pediatric Neurology of Centro Hospitalar Lisboa Central (Lisbon, Portugal) or to the Clinical Neurophysiology Department of Centro Hospitalar Psiquiátrico de Lisboa (Lisbon, Portugal), with the suspicion of CSWS. In all cases, cognitive and/or behavioral problems were associated with a sleep EEG demonstration of strong increase in spike activity at sleep onset and throughout. The diagnosis of CSWS was established by demonstrating a sudden increase in the spike index (SI) to values higher than $85 \%$ in the transition from wakefulness to the first cycle of sleep in a $24 \mathrm{~h}$ aEEG using the full 10-20 system. Cases where it was not possible to record an all-night EEG or with abundant spike activity while awake were excluded.

Clinical and neurophysiological data for each patient are presented in Table 1.

\subsection{EEG recordings}

Recordings with the full 10-20 system were obtained in a clinical context using a medical grade aEEG system (TREX HD, XLTEK@), with sampling at $200 \mathrm{~Hz}$ and bandwidth $0.5-70 \mathrm{~Hz}$. Both the timing and the number of recordings were freely determined by the clinical neurologists as they saw fit to support clinical decisions. Most studies lasted $24 \mathrm{~h}$, but in four cases, it was extended to $67 \mathrm{~h}$, including 3 whole nights (Fig. 1b). Gold-plated disk-type Grass electrodes were applied with collodion and impedances adjusted to less than $5 \mathrm{kohm}$.

\subsection{Spike quantification}

The spike quantification was performed in the CURRY6 software (Neuroscan-Compumedics) and MatLab (R2018a) and included the following steps (Fig. 1a):

Visual inspection by an experienced clinical neurophysiologist of the raw EEG and selection of representative spikes to quantify.

Offline automatic template match search of similar spikes in the whole recording.

Selection of spikes with higher than $85 \%$ correlation and $60 \%$ peak amplitude with respect to the template spike.

The peak detection time of the remaining spikes was used as input to the script published by Larsson et al. [5], running in Matlab. Epochs of $3 \mathrm{~s}$ were used for discretizing the trace in on-off periods, [10], and the percentage off on periods in 200 consecutive epochs, yielding a SI number for each $10 \mathrm{~min}$ of recording.

The maximum SI for each of the first four sleep cycles were determined and averaged to obtain avgSI. The first, maxSI1, and fourth,
maxSI4, were also individually selected. Those three parameters were used to represent each assessment of SI.

\subsection{Clinical response}

The clinical response (CR) to therapeutic trials was retrospectively obtained from the individual medical records of each patient, with an emphasis on information on developmental milestones, behavior, interpersonal interaction, and school performance. The clinical impression was formulated by a medical clinical neurophysiologist (AL) and was used to classify each therapeutic trial into one of three options: no CR (no improvement in behavior or school performance), fair CR (detectable improvement in one of the previous two domains), and good CR (clear improvement in both behavioral and school performances).

\subsection{Wearable EEG device}

One of the authors (TM) constructed a logger (Neury) with the capability to continuously acquire and store EEG from two bipolar channels at $200 \mathrm{~Hz}$ (band-with $0.5-70 \mathrm{~Hz}$ ), using standard scalp disk electrodes. The device uses an Intan Technologies RHD2216 amplifier chip, and the data are stored in an internal memory ( $128 \mathrm{MB}$ ). The dimensions are 53 $\times 32 \times 15 \mathrm{~mm}$, and the weight is $35 \mathrm{~g}$, including an internal Li-ion rechargeable battery (Fig. 3c). During the procedure, the device is attached to the chest of the patients below the clavicle, using a snap EKG gel electrode which can also function as electrical ground. For the validation studies, the electrodes of the logger were applied $1 \mathrm{~cm}$ apart from electrode positions of a medical grade aEEG device (TREX, XLTEK $\left.{ }^{\circledR}\right)$ so that EEG from the two devices could be compared for the various rhythms and graphic elements.

The position of electrodes on the scalp was established by the clinical neurophysiologist with the aim of recording with the maximal amplitude the spikes selected for quantification in previous clinical sleep EEG recordings (either short- or long-term). At the end of the recording, the EEG signal is downloaded to a PC through a mini-USB port connection in the device. The study has been approved by the ethics committee of Centro Hospitalar Psiquiátrico de Lisboa..

\section{Results}

\subsection{Stability of spike maps and temporal profiles in CSWS}

In order to evaluate the variability of SI in multiple quantifications, we compared its parameters in two assessments months apart (average: 1.14 years) in the same patient, with no changes in drug therapy. Of the three parameters tested, the avgSI proved to be the one with less variability in the 10 patients tested (Fig. 1c), with a range between assessments of -6.6 to $+13 \%$ (Fig. 1c).

In general, the spike topography of the most abundant spikes used as templates was similar in the two assessments, except for one patient in which bilateral independent central-parietal spikes shifted hemisphere dominance between studies.

The daily variability was studied in four patients, with continuous recordings spanning three nights. A similar profile of the SI can be seen for the successive nights and naps of each patient (Fig. 1b, left), but some changes in the avgSI can be appreciated (Fig. 1b, right).

\subsection{Variation of spike temporal profile with therapy}

The effect of pharmacological therapy on the SI profile was studied using the avgSI, as this was the parameter with less variability in the previous assessments. In Fig. 2, the changes after the most used therapies are shown, together with the range of temporal variability previously determined (Fig. 1c).

In 8 of the 10 patients submitted to corticosteroids, it was possible to reduce the avgSI to a value lower than the previous range of normal 
Table 1

Patient data.

\begin{tabular}{|c|c|c|c|c|c|c|c|c|c|c|c|c|c|}
\hline \multirow[t]{2}{*}{ Patients } & \multirow[t]{2}{*}{ Age } & \multirow[t]{2}{*}{ Sex } & \multicolumn{3}{|c|}{ Epilepsy } & \multicolumn{4}{|l|}{ EEG } & \multirow{2}{*}{$\begin{array}{l}\text { Imaging } \\
\text { MRI }\end{array}$} & \multicolumn{3}{|c|}{ Therapy for CSWS* } \\
\hline & & & $\begin{array}{l}\text { Age } \\
\text { onset }\end{array}$ & Seizure type & $\begin{array}{l}\text { Cognitive/behavioral } \\
\text { impairment }\end{array}$ & Baseline & Spike topogr & $\begin{array}{l}1 \mathrm{st} \\
\mathrm{aEEG}\end{array}$ & $\begin{array}{l}\mathrm{Nr} \\
\mathrm{aEEGs}\end{array}$ & & Corticosteroids & Sulthiame & $\begin{array}{l}\text { Ketogenic } \\
\text { diet }\end{array}$ \\
\hline & 9 & M & $5 y$ & CPS $>$ GTCS & School performance & $\mathrm{N}$ & Right occipital & $7 y$ & 6 & Normal & $9 \mathrm{~m}(8 \mathrm{y})$ & & \\
\hline 2 & 10 & $\mathrm{~F}$ & $4 \mathrm{y}$ & $\begin{array}{l}\text { CPS + eye } \\
\text { deviation }\end{array}$ & & $\mathrm{N}$ & $\begin{array}{l}\text { Right } \\
\text { temporal-occipital }\end{array}$ & $5 \mathrm{y}$ & 1 & Normal & & & \\
\hline 3 & 14 & $\mathrm{~F}$ & $3 y$ & $\begin{array}{l}\text { Nocturnal } \\
\text { PMS }\end{array}$ & $\begin{array}{l}\text { School performance, } \\
\text { attention }\end{array}$ & $\mathrm{N}$ & Vertex & $8 \mathrm{y}$ & 2 & Normal & & & \\
\hline 4 & 20 & M & $5 y$ & CPS & Language, memory & $\mathrm{N}$ & Left central & $9 y$ & 3 & Thal lesion & $12 \mathrm{~m}(10 \mathrm{y})$ & & $6 \mathrm{~m}(11 \mathrm{y})$ \\
\hline 5 & 7 & $\mathrm{~F}$ & $4 y$ & CPS & None & $\mathrm{N}$ & Bilateral occipital & $6 y$ & 1 & Normal & & & \\
\hline 6 & 15 & $\mathrm{~F}$ & $8 \mathrm{y}$ & PMS > GTCS & Language & $\mathrm{N}$ & Bilateral central & $8 \mathrm{y}$ & 2 & Normal & & & \\
\hline 7 & 16 & $\mathrm{~F}$ & $5 y$ & PMS & School performance & $\mathrm{N}$ & Vertex & $9 y$ & 2 & Thal lesion & & & $6 \mathrm{~m}(9 \mathrm{y})$ \\
\hline 8 & 11 & $\mathrm{~F}$ & $4 \mathrm{y}$ & Aphasic & $\begin{array}{l}\text { Language, moderate } \\
\text { delay }\end{array}$ & $\mathrm{N}$ & $\begin{array}{l}\text { Left posterior } \\
\text { quadrant }\end{array}$ & $5 \mathrm{y}$ & 7 & Normal & $12 \mathrm{~m}(8 \mathrm{y})$ & & \\
\hline 9 & 15 & M & $2 \mathrm{y}$ & PMS + CPS & Moderate delay & $\mathrm{N}$ & Bilateral central & $8 \mathrm{y}$ & 3 & Normal & & $\begin{array}{l}12 \mathrm{~m}(8 \\
\mathrm{y})\end{array}$ & \\
\hline 10 & 9 & M & $4 \mathrm{y}$ & CPS $>$ GTCS & Moderate delay & $\mathrm{N}$ & $\begin{array}{l}\text { Right posterior } \\
\text { quadrant }\end{array}$ & $8 \mathrm{y}$ & 1 & $\begin{array}{l}\text { Right hemisph } \\
\text { stroke }\end{array}$ & & & \\
\hline 11 & 11 & M & $5 y$ & PMS > GTCS & School performance & $\mathrm{N}$ & Right temporal & $8 \mathrm{y}$ & 4 & None & & $(8 \mathrm{y})^{* *}$ & \\
\hline 12 & 16 & M & $8 \mathrm{y}$ & $\begin{array}{l}\text { Nocturnal } \\
\text { PMS }\end{array}$ & Attention & $\mathrm{N}$ & Vertex & $9 \mathrm{y}$ & 3 & Normal & & & \\
\hline 13 & 16 & M & $7 \mathrm{y}$ & GTCS & $\begin{array}{l}\text { School performance, } \\
\text { language }\end{array}$ & $\mathrm{N}$ & Left temporal & $8 \mathrm{y}$ & 3 & $\begin{array}{l}\text { Without } \\
\text { registration }\end{array}$ & & $\begin{array}{l}24 \mathrm{~m}(9 \\
\mathrm{y})\end{array}$ & \\
\hline 14 & 11 & M & $8 \mathrm{y}$ & CPS $>$ GTCS & $\begin{array}{l}\text { School performance, } \\
\text { aggression }\end{array}$ & $\mathrm{N}$ & $\begin{array}{l}\text { Left central }+ \\
\text { temporal }\end{array}$ & $9 \mathrm{y}$ & 7 & Normal & $6 \mathrm{~m}(9 \mathrm{y})$ & $8 \mathrm{~m}(8 \mathrm{y})$ & \\
\hline 15 & 11 & $\mathrm{~F}$ & $2 \mathrm{y}$ & PMS & None & $\mathrm{N}$ & Vertex & $5 \mathrm{y}$ & 2 & Normal & & & \\
\hline 16 & 12 & $\mathrm{~F}$ & $3 y$ & PMS > GTCS & School performance & $\mathrm{N}$ & Vertex & $6 y$ & 6 & Normal & $14 \mathrm{~m}(4 \mathrm{y})$ & $(5 y)^{* *}$ & \\
\hline 17 & 8 & $\mathrm{~F}$ & & PMS > GTCS & Severe delay & $\mathrm{N}$ & $\begin{array}{l}\text { Right posterior } \\
\text { quadrant }\end{array}$ & $7 y$ & 1 & $\begin{array}{l}\text { Brain } \\
\text { malformation }\end{array}$ & & & \\
\hline 18 & 25 & M & $3 y$ & PMS & None & $\mathrm{N}$ & $\begin{array}{l}\text { Right posterior } \\
\text { quadrant }\end{array}$ & $10 \mathrm{y}$ & 1 & Thal lesion & & & \\
\hline 19 & 14 & M & $8 \mathrm{~m}$ & PMS & Moderate delay & $\mathrm{N}$ & Left frontal & $8 \mathrm{y}$ & 3 & Thal lesion & & & \\
\hline 20 & 16 & M & $7 \mathrm{~m}$ & PMS + CPS & Severe delay & $\mathrm{N}$ & $\begin{array}{l}\text { Right posterior } \\
\text { quadrant }\end{array}$ & $10 \mathrm{y}$ & 7 & Thal lesion & & $(11 \mathrm{y})^{* *}$ & \\
\hline 21 & 11 & $\mathrm{~F}$ & $4 y$ & Aphasic & Sensory aphasia & $\mathrm{N}$ & $\begin{array}{l}\text { Left posterior } \\
\text { quadrant }\end{array}$ & $4 y$ & 1 & Normal & & & \\
\hline 22 & 11 & M & $2 \mathrm{y}$ & PMS & School performance & $\mathrm{N}$ & $\begin{array}{l}\text { Right posterior } \\
\text { quadrant }\end{array}$ & $8 \mathrm{y}$ & 4 & Thal lesion & $(9 y)^{* *}$ & & \\
\hline 23 & 10 & $\mathrm{~F}$ & & $\begin{array}{l}\text { Nocturnal } \\
\text { PMS }\end{array}$ & Moderate delay & $\mathrm{N}$ & Right central & $8 \mathrm{y}$ & 1 & Normal & & & \\
\hline 24 & 9 & $\mathrm{~F}$ & $2 \mathrm{y}$ & PMS & Aphasia & $\mathrm{N}$ & Left temporal & $3 y$ & 2 & Normal & & & \\
\hline 25 & 9 & M & - & - & Aphasia & $\mathrm{N}$ & $\begin{array}{l}\text { Bilateral } \\
\text { temp-parietal }\end{array}$ & $6 y$ & 1 & $\begin{array}{l}\text { Mild } \\
\text { hydrocephalus }\end{array}$ & & & \\
\hline 26 & 11 & M & $4 y$ & PMS & Sensory aphasia & $\mathrm{N}$ & Left temporal & $5 \mathrm{y}$ & 3 & Normal & & & \\
\hline 27 & 16 & M & $4 y$ & $\begin{array}{l}\text { Nocturnal } \\
\text { PMS }\end{array}$ & $\begin{array}{l}\text { Language, diplegic } \\
\text { cerebral palsy }\end{array}$ & $\mathrm{N}$ & $\begin{array}{l}\text { Bilateral } \\
\text { central-parietal }\end{array}$ & $9 y$ & 3 & Normal & & & \\
\hline 28 & 17 & M & $4 y$ & PMS & Sensory aphasia & $\mathrm{N}$ & $\begin{array}{l}\text { Left posterior } \\
\text { quadrant }\end{array}$ & $5 y$ & 7 & Normal & $12 \mathrm{~m}(6 \mathrm{y})$ & & \\
\hline 28 & 10 & $\mathrm{~F}$ & $1 \mathrm{y}$ & PMS + CPS & None & $\mathrm{N}$ & Vertex & $10 \mathrm{y}$ & 2 & Thal lesion & & & \\
\hline 30 & 9 & M & - & - & $\begin{array}{l}\text { School performance, } \\
\text { attention, aggression }\end{array}$ & $\mathrm{N}$ & Bilateral central & $8 \mathrm{y}$ & 1 & Normal & & & \\
\hline 31 & 12 & $\mathrm{~F}$ & $2 \mathrm{y}$ & PMS > GTCS & School performance & $\mathrm{N}$ & $\begin{array}{l}\text { Right posterior } \\
\text { quadrant }\end{array}$ & $8 \mathrm{y}$ & 7 & Thal lesion & $5 \mathrm{~m}(8 \mathrm{y})$ & & \\
\hline 32 & 6 & M & $1 \mathrm{y}$ & $\begin{array}{l}\text { Nocturnal } \\
\text { PMS }\end{array}$ & & $\mathrm{N}$ & Right central & $10 \mathrm{y}$ & 1 & Normal & & & \\
\hline 33 & 10 & M & $4 y$ & $\begin{array}{l}\text { Nocturnal } \\
\text { PMS }\end{array}$ & Attention, language & $\mathrm{N}$ & Left central & $4 y$ & 5 & Normal & & $\begin{array}{l}12 \mathrm{~m}(5 \\
\mathrm{y})\end{array}$ & \\
\hline 34 & 12 & M & & $\begin{array}{l}\text { Nocturnal } \\
\text { PMS }\end{array}$ & & $\mathrm{N}$ & Right central & $9 y$ & 5 & Normal & $6 \mathrm{~m}(9 \mathrm{y})$ & & $\begin{array}{l}12 \mathrm{~m}(10 \\
\mathrm{y})\end{array}$ \\
\hline 35 & 11 & $\mathrm{~F}$ & $1 \mathrm{y}$ & $\mathrm{CPS}+\mathrm{SPS}$ & General delay & Slow & $\begin{array}{l}\text { Right posterior } \\
\text { quadrant }\end{array}$ & $2 \mathrm{y}$ & 2 & Thal lesion & & & \\
\hline 36 & 3 & $\mathrm{~F}$ & $2 \mathrm{y}$ & PMS & $\begin{array}{l}\text { Language, autistic } \\
\text { regression }\end{array}$ & Slow & Left central & $3 y$ & 1 & None & & & \\
\hline
\end{tabular}


Table 1 (continued)

\begin{tabular}{|c|c|c|c|c|c|c|c|c|c|c|c|c|c|}
\hline \multirow[t]{2}{*}{ Patients } & \multirow[t]{2}{*}{ Age } & \multirow[t]{2}{*}{ Sex } & \multicolumn{3}{|c|}{ Epilepsy } & \multicolumn{4}{|l|}{ EEG } & \multirow{2}{*}{$\frac{\text { Imaging }}{\text { MRI }}$} & \multicolumn{3}{|c|}{ Therapy for CSWS* } \\
\hline & & & $\begin{array}{l}\text { Age } \\
\text { onset }\end{array}$ & Seizure type & $\begin{array}{l}\text { Cognitive/behavioral } \\
\text { impairment }\end{array}$ & Baseline & Spike topogr & $\begin{array}{l}1 \mathrm{st} \\
\mathrm{aEEG}\end{array}$ & $\begin{array}{l}\mathrm{Nr} \\
\mathrm{aEEGs}\end{array}$ & & Corticosteroids & Sulthiame & $\begin{array}{l}\text { Ketogenic } \\
\text { diet }\end{array}$ \\
\hline \multirow{2}{*}{37} & 8 & M & $4 \mathrm{y}$ & PMS & Language & $\mathrm{N}$ & $\begin{array}{l}\text { Left } \\
\text { temporal-parietal }\end{array}$ & $3 y$ & 8 & Normal & \multirow{2}{*}{\multicolumn{3}{|c|}{$\begin{array}{l}13 \mathrm{~m}(5 \mathrm{y}), 8 \\
\mathrm{~m}(7 \mathrm{y})\end{array}$}} \\
\hline & 4 & M & - & - & Language, aggression & $\mathrm{N}$ & Left central & $4 \mathrm{y}$ & 1 & None & & & \\
\hline
\end{tabular}

CPS-complex partial seizures; PMS-partial motor seizures; GTCS-generalized tonic-clonic seizures; aEEG-ambulatory EEG.

* Duration in months $(\mathrm{m})$, age of onset in years $(\mathrm{y})$.

** Ongoing therapy.

variability and, therefore, to produce a meaningful neurophysiology response (Fig. 2a). The time necessary to obtain a response proved highly variable, with some patients reaching it after 3-4 months (patients P1 and P37) while others only achieved it after longer periods (P26 and P14). The amount of the response was also very variable, with some patients demonstrating a strong one (P1 and P37), while in the remaining, it was more modest.

Four of the responders presented with a late recurrence (P1, P8, P22, P34). The two nonresponders (P16, P26) were only assessed long after therapy onset, and so we cannot exclude that a short-term response might have occurred.

The 7 patients submitted to therapy with sulthiame showed meaningful responses in 4 cases, which were more modest in amplitude than the ones for corticosteroids (Fig. 2b). A notable exception was patient P13 who exhibited a strong response.

In three patients submitted to ketogenic diet, it was not possible to demonstrate a meaningful neurophysiological response (Fig. 2c). Nevertheless, the follow-up is short on two cases, which precludes a definitive statement.

An important limitation of the previous analysis is imposed by the sparse assessments after therapy, which is probably a multifactorial consequence of poor tolerability of the child population to repeated aEEG recordings and to the economic burden associated with such studies.

\subsection{Correlation of temporal spike profiles from full 10-20 and 2 bipolar channel montages}

In order to simplify the process of repeated assessments of the SI parameters, we performed quantification of these parameters using the full set of 10-20 electrodes and a reduced set of 2 bipolar channels obtained from the same pretreatment recordings. The two bipolar channels were composed individually for each patient in order to maximize the amplitude of the spikes that the clinical neurophysiologist considered adequate for quantification.

Results of the paired comparison of the avgSI for 19 and 2-channel datasets are represented in Fig. 3a and demonstrate a range from -8.2 to $+7.4 \%$ with an average difference of $-1.8 \%$. A paired t-test produced a score of 0.0617 which leads to acceptance of the null hypothesis of no difference between the two dataset means at $\mathrm{p}<0.05$.

\subsection{Validation of Neury 2-channel recording with simultaneous 10-20 montage}

The good overlap of the SI obtained from the full 10-20 datasets and a selected 2 bipolar channel montage led us to design a wearable device (Fig. 3c), able to record two bipolar channels with medical grade quality for $24 \mathrm{~h}$, with the goal of simplifying the process of quantification of spike activity in the clinical setting.

The Neury device was validated against a medical grade aEEG recorder in a group of healthy subjects and then in patients with epilepsy submitted to clinical studies. A side by side comparison of the background rhythms and spike activity revealed an excellent concordance between the two devices, which was also apparent when comparing ictal recordings (Fig. 3b, below)

The typical application time of the Neury device, including connection of 4 electrodes on the scalp with collodium and placement on an ECG chest snap electrode, which functions both as electrical ground and support for the device, was around 15 min. This was much less than the typical 60-90 min for setting up the full 10-20 system montage. The tolerability of the Neury device was also reported as excellent by the patients, with no interference reported in the daily activities.

The comparison of the SI obtained from the medical grade device and the Neury in patients with CSWS was within the variation range of the previously performed comparison of 19 referential to 2 bipolar electrodes (Fig. 3d), with an average difference of $-2.8 \%$.

\section{Discussion}

The quantification of the SI in a group of patients with CSWS highlighted the ability to simplify the conventional methodology with the use of a small wearable EEG logger, with a relevant reduction of the recording preparation time and improved tolerability, both of which can contribute to increasing patient adherence to a more frequent sampling of the SI throughout the natural history of the condition, allowing a better characterization of the natural and therapy-induced changes in the SI.

The analysis of the SI in our group of patients demonstrated an interindividual variability which was of the same magnitude of the one found in previous studies (reviewed in [8]), ranging from average values higher than $85 \%$ to values less than $50 \%$ (Fig. 3a). The individual variation of the SI in the same patient several months apart, with no change in therapy, was much less (Fig. 1c) than the day-to-day variability (Fig. 1b). Our observations support the usefulness of individual assessments of the SI throughout the natural history of the syndrome as an effective monitoring method and provide us with normality ranges of variability to evaluate the effectiveness of therapeutic trials to reduce the spike activity at the heart of the CSWS.

The follow-up of SI in cases submitted to the most common therapies supports the well-known higher effectiveness of corticosteroids over both sulthiame and the ketogenic diet (reviewed in [7]) (Fig. 2), but most importantly puts in evidence a high variability in both the amount of the response and the time required to achieve it in individual patients. In the data from Fig. 2, a clear trend for recurrence of spike activity after stopping corticosteroids, which likely heralds clinical deterioration, can also be found. A more detailed assessment of the individual profile of the responses to therapy onset and offset would benefit from a more frequent sampling of the SI than the one typically used in our study and in most clinics at the present time. Such improved sampling would provide the chance to determine the temporal relation between changes in the SI and clinical worsening/improvement, which is not possible in our current study because of the sparse SI determinations available.

Because of the significant morbidity associated with corticosteroids, and the need for long-term trials, a fast and consistent method of assessing the clinical effects is highly desirable so that doses can be 

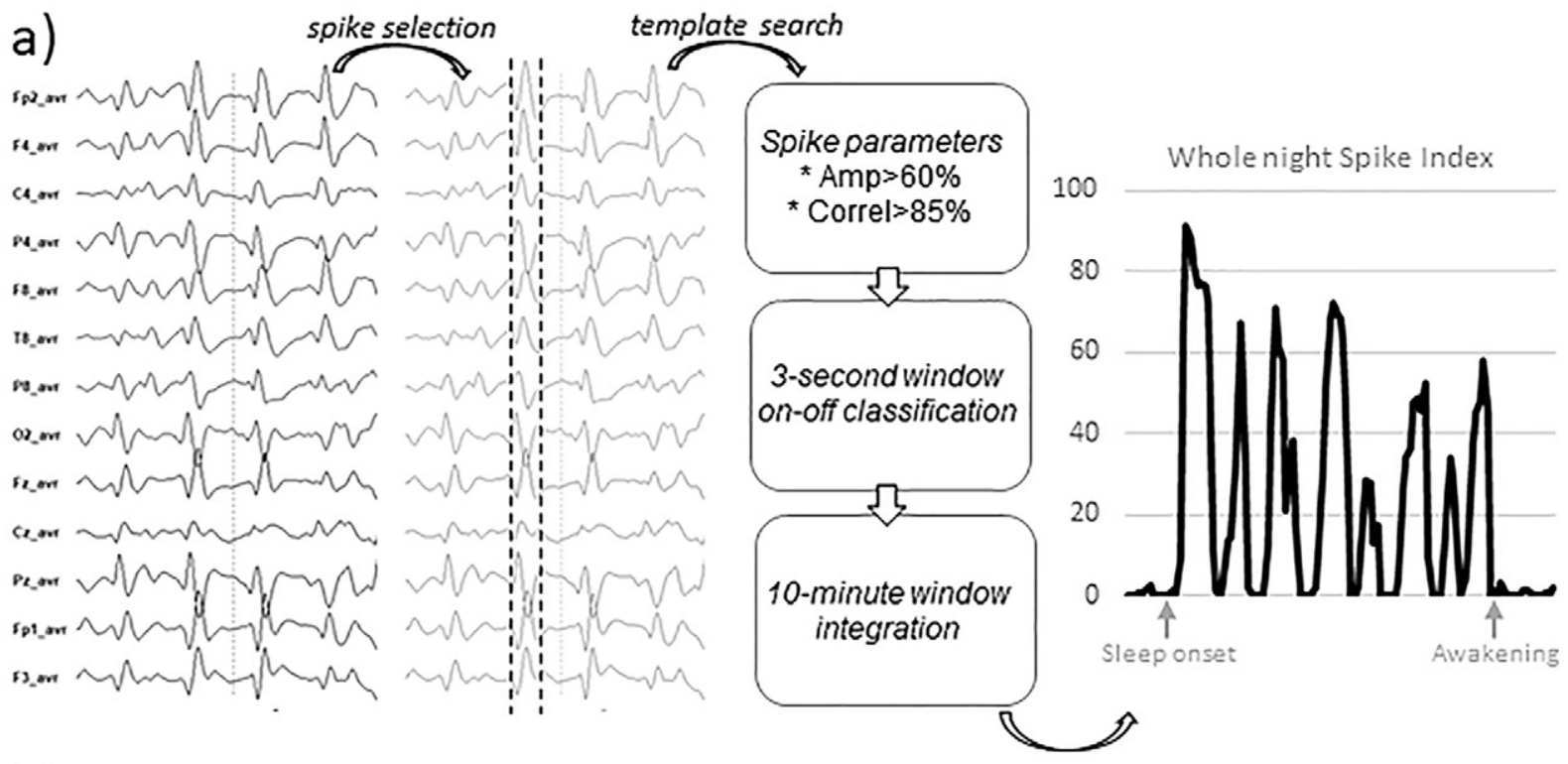

b) Temporal stability (days, $\mathrm{N}=4$ )
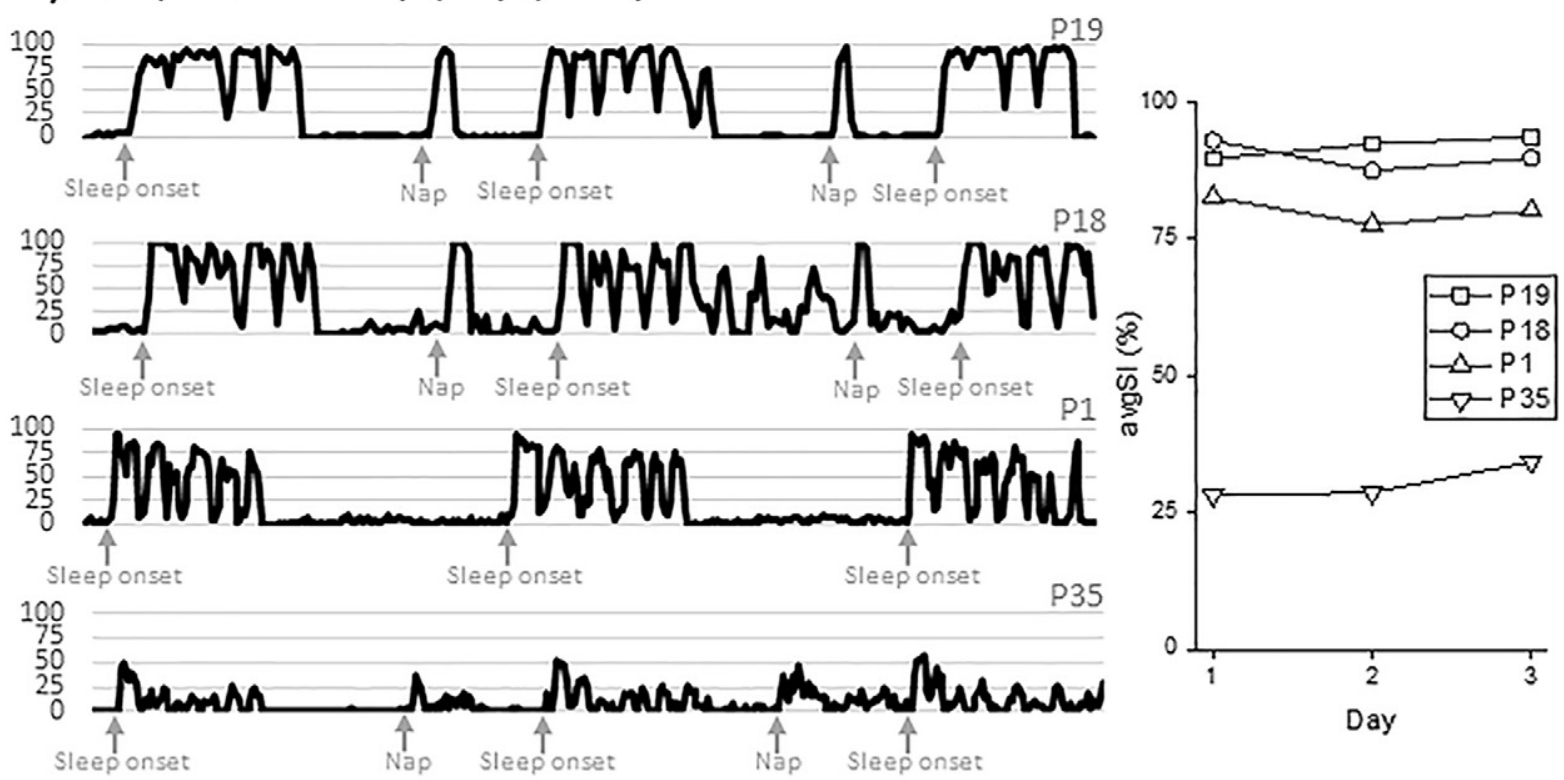

c) Temporal stability (months, $\mathrm{N}=10$ )
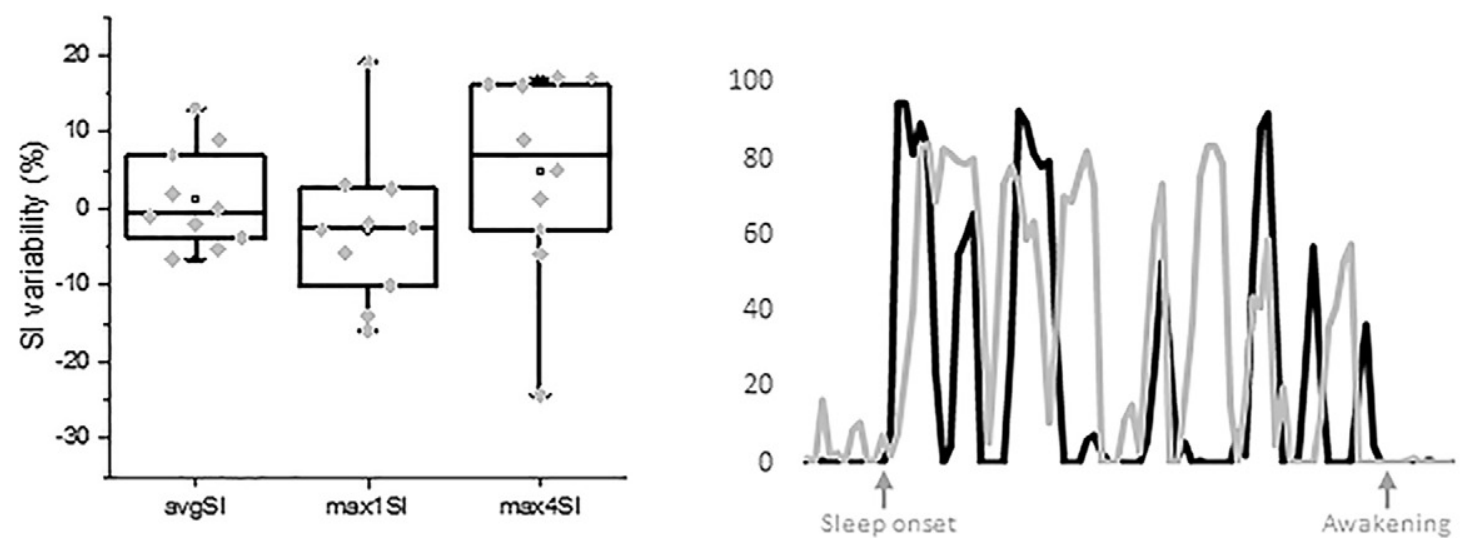

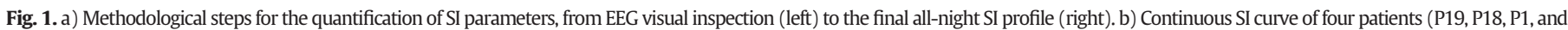

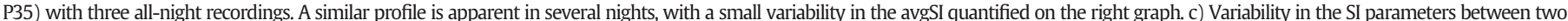

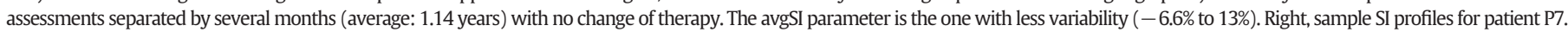


a)

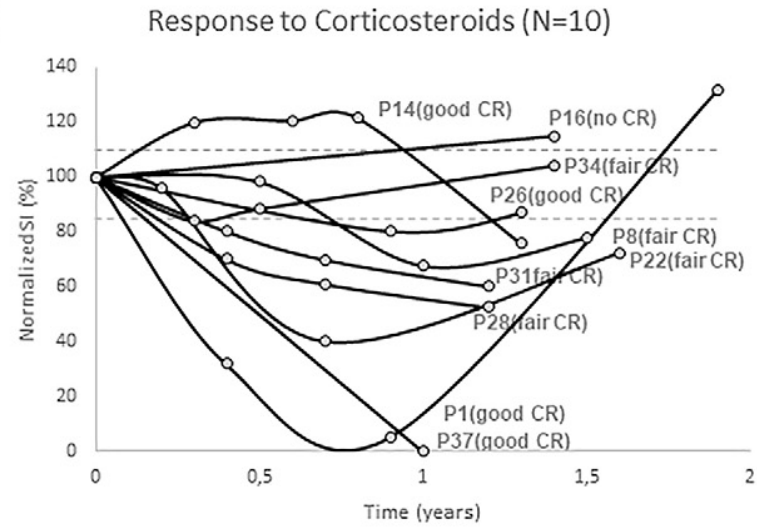

b)

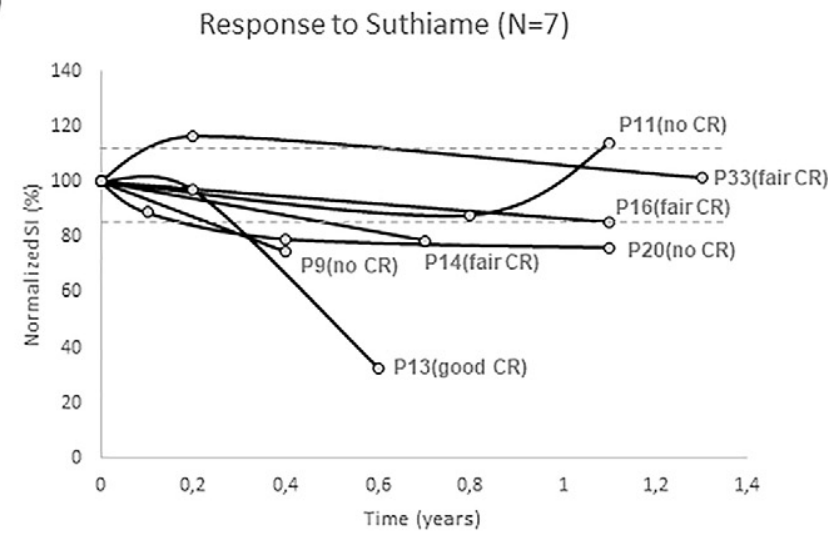

c)

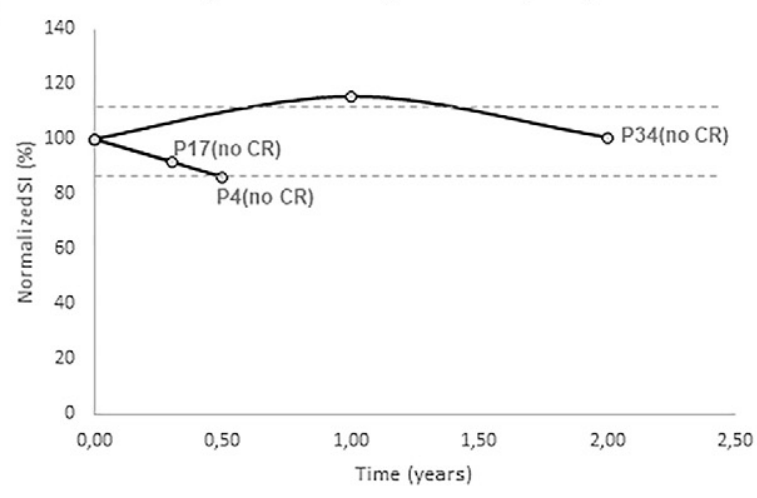

Fig. 2. a) Evolution of the avgSI under therapy with corticosteroids. The duration of therapy was variable between patients, ranging from 5 to 29 months (average: 10.6). The normalized avgSI range time course (dotted lines in gray), revealed widely variable maximum effect of therapy and also a variable time of onset of the neurophysiological response. In 4 patients, a recurrent pattern after an early response is apparent in the follow-up (P1, P22, P26, P8). b) Response for therapy with sulthiame puts in evidence a more modest response in the avgSI, except for patient P13, which demonstrated a strong reduction in the parameter. c) The ketogenic diet produced no clear response, but a reduced number of patients and assessments are available.

kept to an effective minimum. The conventional method of relying on cognitive/behavioral or school performance improvements to adjust therapy suffers from the well-known delay of these indicators in relation to neurophysiological spike quantifications [3]. We therefore propose that more frequent quantification of the SI can have an important role in timely adjustment of pharmacological therapies, particularly in the ones associated with important secondary effects.

The ability to simplify the quantification of the SI with the use of a reduced set of scalp electrodes relies on the spatial stability of spike activity throughout time. Our studies [11] and other's (reviewed in [12]) suggest that the spike activity associated with CSWS remains focalized in most patients, if care is taken to correct the confusing effect of secondary propagation patterns associated with the onset of sleep. Nevertheless, in a few cases, a clear shift in the dominant focus is apparent in repeated assessments [13]. In order to overcome this possibility, we recommend the association of a conventional nap recording, which can provide a sensitive assessment of the spike pattern of the first cycle of sleep [4] and inform on the spatial distribution of the dominant spike activity, with a full 24-h SI assessment.

Repeated all-night quantifications of the SI are clearly more accurate that extrapolations obtained from conventional nap recordings which only sample the first cycle of sleep (reviewed in [4]). Some patients demonstrate a clear decrease in later cycles, and a good response to therapy can, at an early stage, be limited to those late stages of sleep and not be apparent in the first one [8].

The proposed wearable device takes advantage of the reduced number of electrodes required for SI quantification, to minimize the weight and inconvenience associated with conventional full 10-20 ambulatory recorders. The additional benefits in preparation time, portability, reduced social impact, and freedom of movement are particularly welcome to improve the tolerability [14] to repeated assessments in the typical child with CSWS.

The simplification of SI quantification to a set of 2 bipolar electrodes proved effective to sample the dominant spike patterns associated with CSWS in our patients, and the improved signal-to-noise ratio obtained by optimizing spike amplitudes with the individual tuning also made more robust the selection of the more adequate spike to perform the crucial template matching automatic search for spikes. This benefit is obtained at the expense of decreased sensitivity to less dominant spikes that might be present.

At the present stage, we feel that a more consistent quantification of the $\mathrm{SI}$ is obtained by selecting individual spike types (eventually more than one per patient) and performing a template match search, than quantifying all spikes together, because not all types show the same sensitivity to sleep onset [13] and mixing different types can increase noise in the data. An additional factor that plays against detecting all spikes together relates to the fact that during sleep, secondary propagation patterns frequently arise, which can artificially increase detections and further compromise an accurate quantification.

Limitations of the paper are fundamentally its exploratory and retrospective character, which relied on clinical decisions on the timing of the SI quantifications and therefore led to nonuniform sampling across the diverse patients. This limitation nevertheless highlights current clinical practices, where no clinical guidelines are presently established on the most appropriate strategy, and supports our suggestion that a more frequent sampling would certainly result in a more accurate and clinically useful understanding of the individual time course of spike activity. Also, the heterogeneous number of patients in the different therapeutic groups precludes an unbiased comparison among them. Our goal in this respect was not so much to make this comparison but instead to demonstrate the large variability in individual responses, which could benefit from more frequent SI determinations.

\section{Declaration of competing interest}

None.

\section{Acknowledgments}

The authors are grateful to several pediatric neurologists who have referred the patients for neurophysiological studies and provided us with information on the results of the therapeutic trials performed. Funding for development of the EEG logger has been provided by a grant from AL Neurofisiologia Lda. 
a)

Comparison SI (19-2 Ch)
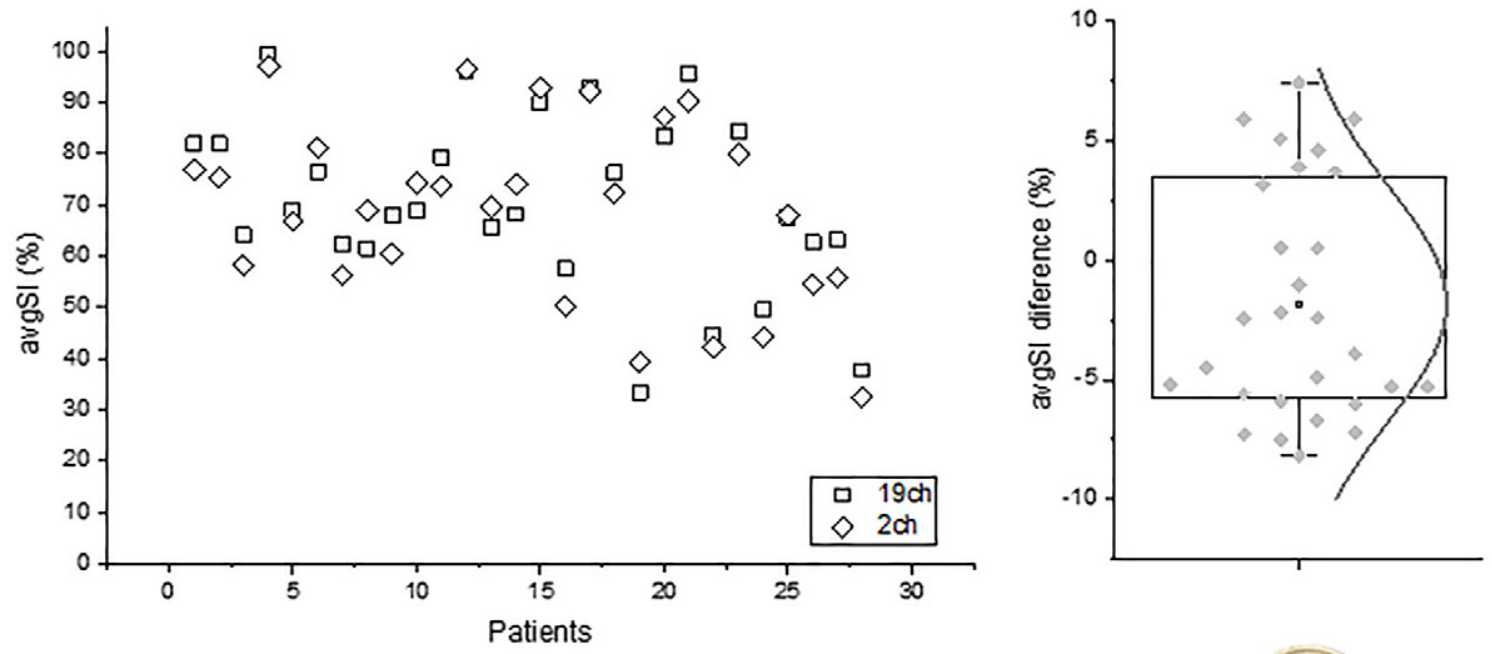

b)

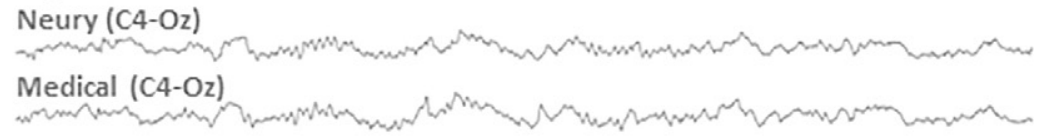

Neury $\left(\mathrm{C}^{*}-\mathrm{F} 3^{*}\right)$

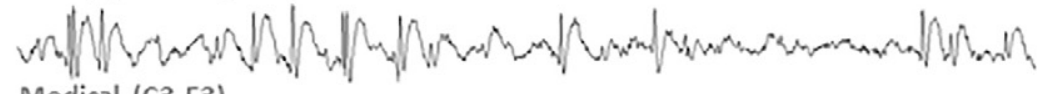
Medical (C3-F3)

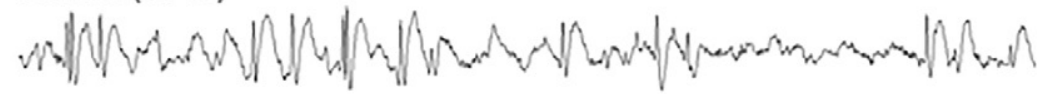

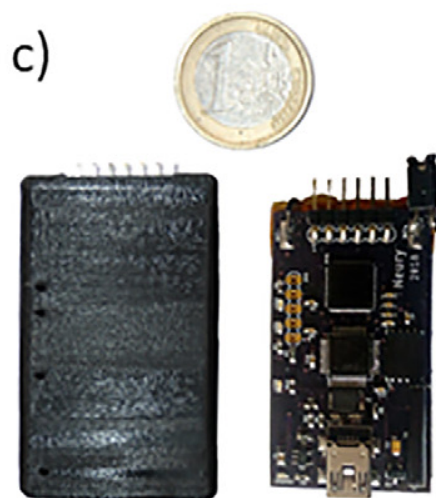

Neury (FT7-FCz

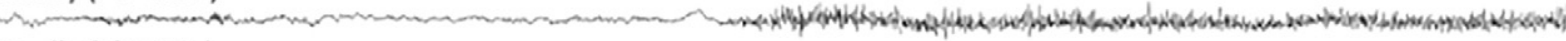
Medical (F7-FCZ)

Hat

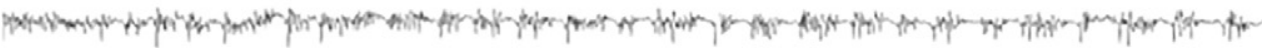

d)
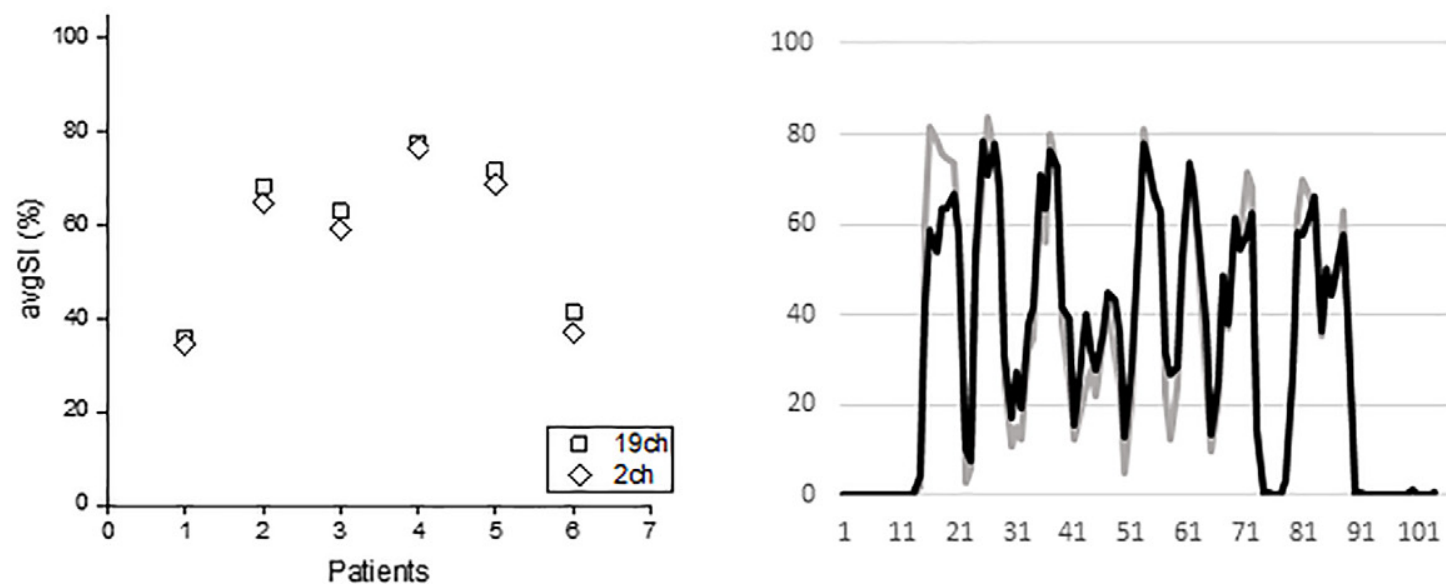

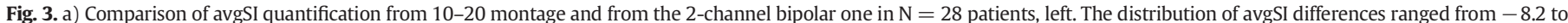

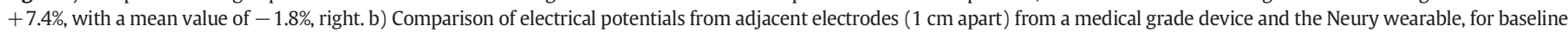

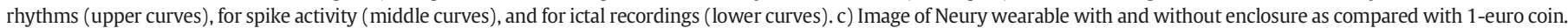

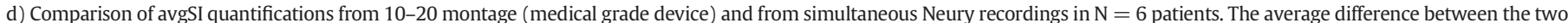
sets of data was $-2.8 \%$. Example of two all-night avgSI profiles obtained from the two devices used simultaneously in patient P14, right. 


\section{References}

[1] Patry G, Luagoubi S, Tassinari C. Subclinical "electrical status epilepticus" induced by sleep in children. A clinical and electroencephalographic study of six cases. Arch Neurol 1971;24:242-52. https://doi.org/10.1001/archneur.1971.00480330070006.

[2] Dorris L, O'Regan M, Wilson M, Zuberi S. Progressive intellectual impairment in children with encephalopathy related to status epilepticus during slow sleep. Epileptic Disord 2019;21(Suppl. 1):S88-96. https://doi.org/10.1684/epd.2019.1063.

[3] Maltoni L, Posar A, Parmeggiani A. Long-term follow-up of cognitive functions in patients with continuous spike-waves during sleep (CSWS). Epilepsy Behav 2016;60: 211-7. https://doi.org/10.1016/j.yebeh.2016.04.006.

[4] Boer M. Guidelines for EEG in encephalopathy related to ESES/CSWS in children. Epilepsia 2009·50(Suppl. 7):13-7. https://doi.org/10.1111/j.1528-1167.2009.02211x.

[5] Larsson P, Wilson J, Eeg-Olofsson O. A new method for quantification and assessment of epileptiform activity in EEG with special reference to focal nocturnal epileptiform activity. Brain Topogr 2009;22:52-9. https://doi.org/10.1007/s10548-008-0072-3.

[6] Tassinari C, Rubboli G. Encephalopathy related to status epilepticus during slow sleep: current concepts and future directions. Epileptic Disord 2019;21(Suppl. 1): S82-7. https://doi.org/10.1684/epd.2019.1062.

[7] Jansen F, Nikanorova M, Peltola M. Current treatment options for encephalopathy related to status epilepticus during slow sleep. Epileptic Disord 2019;21(S1): S76-81. https://doi.org/10.1684/epd.2019.1061.
[8] Cantalupo G, Pavlidis E, Beniczky S, Avanzini P, Gardella E, Larsson P. Quantitative EEG analysis in encephalopathy related to status epilepticus during slow sleep. Epileptic Disord 2019;21(S1):S1-S10. https://doi.org/10.1684/epd.2019.1055.

[9] Gardella E, Kolmel M, Temey D, Petersen Khinchi M, Pavlidis E, Olofsson K, et al. Afetrnoon nap vs. all-night sleep EEG for the diagnosis of ESES. Epilepsia 2016;57 (Suppl. 2):77. https://doi.org/10.1111/epi.13609.

[10] Peltola M, Palmu K, Liukkonen E, Gaily E, Vanhatalo S. Semiautomatic quantification of spiking in patients with continuous spikes and waves in sleep: sensitivity to settings and correspondence to visual assessment. Clin Neurophysiol 2012;123(7): 1284-90. https://doi.org/10.1016/j.clinph.2011.12.001.

[11] Leal A, Calado E, Vieira JP, Mendonç C, Ferreira JC, Ferreira H, et al. Anatomical and physiological basis of continuous spike-wave of sleep syndrome after early thalamic lesions. Epilepsy Behav 2018;78:243-55. https://doi.org/10.1016/j.yebeh.2017.08.027.

[12] Gibbs S, Nobili L, Halász P. Interictal epileptiform discharges in sleep and the role of the thalamus in encephalopathy related to status epilepticus during slow sleep. Epileptic Disord 2019;21(Suppl. 1):S54-61. https://doi.org/10.1684/epd.2019.1058.

[13] Gardella E, Cantalupo G, Larsson P, Fontana E, Bernardina B, Rubboli G, et al. EEG features in encephalopathy related to status epilepticus during slow sleep. Epileptic Disord 2019;21(S1):S22-30. https://doi.org/10.1684/epd.2019.1054.

[14] Bruno E, Simblett S, Lang A, Biondi A, Odoi C, Schulze-Bonhage A, et al. Wearable technology in epilepsy: the views of patients, caregivers, and health professionals. Epilepsy Behav 2018;85:141-9. https://doi.org/10.1016/j.yebeh.2018.05.044. 